\title{
Relationship between design floods and land use land cover (LULC) changes in a tropical complex catchment
}

\begin{abstract}
Rainfall characteristics are directly related to the climate of a basin, but this can only be noticed after a long period. Human activities, such as deforestation, tend to play a major role in transforming the land use land cover (LULC). Knowledge of the relationship between design floods and LULC is important in modeling and designing watershed management strategies. A study was conducted in the Kelantan River basin, Malaysia, to determine the impact of past and present LULC changes on peak discharge and runoff volumes. To achieve this, the basin was delineated into four catchments (Galas, Pergau, Nenggiri, and Lebir) due to its size and increased precision. Hydrologic Engineering Center-Hydrologic Modeling System (HECHMS) model was calibrated based on December 20-30th, 2014, flood in Kelantan. Flood hydrographs corresponding to 1984, 2002, and 2013 LULC conditions were simulated, and relative changes in peak discharge and runoff volume were determined for different return periods $(2,5,10,20,50,100$ years). Results of LULC analysis showed that Galas recorded highest deforestation $(54.35 \%)$. When the four catchments were compared with respect to highest contribution of outlet peak discharge, Lebir under 2013 LULC condition was the highest with $2847.70 \mathrm{~m} 3 / \mathrm{s}$. This was followed by Nenggiri $(2196.90 \mathrm{~m} 3 / \mathrm{s})$, Galas (1252.7 $\mathrm{m} 3 / \mathrm{s})$, and Pergau (328.7 m3/s), all under the 2013 LULC condition. Results of unit response approach applied based on 50-year return period to the catchments for ranking their sub-basins revealed that the novel fa index developed in this study provides a better way of ranking subbasins with respect to their contribution to the outlet and therefore is recommended for use. Methodologies developed in this study may be useful to land use planners from around the world which when applied can provide alternatives that will minimize the adverse effects of floods.
\end{abstract}

Keyword: Design floods; Land use land cover changes; Kelantan River basin; GIS; HEC-HMS 